\title{
Prevalence of cervicobrachial discomforts in elementary school teachers
}

\author{
Bruna Angela Antonelli, ${ }^{\mathrm{a},}$ Antonio Augusto de Paula Xavier, ${ }^{\mathrm{b}}$ Paulina Oenning, ${ }^{\mathrm{b}}$ Michel Henrique \\ Baumer, ${ }^{\mathrm{b}}$ Tarcísio Fulgêncio Alves da Silva ${ }^{\mathrm{b}}$ and Luiz Alberto Pilatti ${ }^{\mathrm{b}}$. \\ ${ }^{a}$ Programa de Pós Graduação em Engenharia de Produção: Ergonomia nos processos produtivos. Av. Monteiro \\ Lobato, s/n, 84016-210, Ponta Grossa-PR, Brasil. \\ ${ }^{b}$ Laboratório de Ergonomia, Universidade Tecnológica Federal do Paraná-UTFPR. \\ Bruna_antonelli@yahoo.com.br.
}

\begin{abstract}
Objective: To determine the incidence of cervicobrachial order discomforts in Elementary Public School teachers from 1st to 4th years in the city of Pato Branco - PR. Methods: Cross-sectional study made with 160 public school teachers from 1st to 4th years in the city of Pato Branco - PR. Data collection was made from a structured questionnaire, and a physical examination with manual palpation and orthopedic tests. Results: The obtained data showed the presence of pain in the trapezius muscle region, on the left side, in $52.5 \%$; and, on the right side, in $50.6 \%$. The analysis also showed that there is a strong relationship between the cervicobrachial problems presented and the labor activity. The final evaluation of this study demonstrates the great need of primary care for these workers, that is, carrying out activities to prevent musculoskeletal diseases developed through work, either to preserve the individuals' physical integrity or the quality of education. Conclusions: The prevalence of musculoskeletal disorders was high among teachers. There is evidence that the prevalence was connected to job demands.
\end{abstract}

Keywords: cervicobrachial problems, teachers, quality of life.

\section{Introduction}

An elementary school teacher aims to provide basic training for citizenship by creating learning conditions. So, the teacher must develop the students' ability to learn, to master reading and writing, to understand the natural, social, political and technological environment; these values are fundamental to society [1].

Throughout the seventeenth and eighteenth centuries the genesis of the teaching profession was strongly influenced by some religious beliefs and attiudes which eventually set up a body of knowledge and techniques organized around the principles and strategies of the teaching profession [2]. The social transformations, the educational reforms, and the new teaching models have influenced the working conditions of teachers today, causing changes in the profession. So, the teachers go from a situation of stability and relative security to a situation of insecurity due to new forms of work [3].

With that highlights that teaching work has been done under unfavorable circumstances, under which teachers had to mobilize their physical, cognitive and affective capacities to achieve the school production objectives, thereby requesting their psycho physiological functions [3]. Thus, the teacher's work highlights the teaching role which, by its highly

*Corresponding author. E-mail: bruna_antonelli@yahoo.com.br. 
stressful nature, affects the mental and physical health by interfering with job performance $[3,5,6]$.

The processes of physical and mental dtrain for teachers reflects negatively not only on themselves as professionals but also on the students and on the school system, because working unsuitable conditions may end in a stressing process which results in accumulated tensions [7]. Stress, is the physiological or emotional response to an external stimulus that causes anxiety and tension, leading to some changes such as muscle stiffness especially in the neck, back pain due to long periods standing up in inadequate postures, irritation, fatigue, insomnia, weakness and difficulties to concentrate [8]. These changes lead to inadequate postures in the workplace, and ultimately trigger the overload of the musculoskeletal system, forming a causal link of DORT - Work-Related Musculoskeletal Disorders. (D.O.R.T.) [9].

Elementary school teachers' activities involve the frequent use of the arm above the shoulder to write on the board. Such a mechanism predisposes teachers to start having some kind of discomfort in the cervicobrachial region, which becomes still worse due to daily overwork. High school teachers, on the other hand, hold their classes in a more expository way, following a textbook or a booklet, so they need less writing on the blackboard.

Data exposed show that the most frequent diseases among teachers are respiratory diseases and diseases of the upper limbs, which include: rotator cuff syndrome, synovitis, tenosynovitis, epicondylitis, cervicobrachial syndrome, bursitis, tendinitis and carpal tunnel syndrome [5].

Most of the problems presented by the teachers can be mitigated and / or prevented. Therefore, it is necessary to perform a diagnostic evaluation so you can detect stressors, such as posture and muscle groups more frequently employed when working. From this assessment it is possible to establish the statistics of teachers' symptomatic profile, and to ptovide an occupational disease prevention program for these workers [9].

The etiologic knowledge is of great importance, since one can not make a preventive approach of what hasn't been known yet [10]. The quest for prevention can only occur from the identification of its mechanisms of action, initial signs and symptoms.

From this perspective, the study determines, through a data collection instrument and a physical examination, the cervicobrachial discomforts possibly presented by the teachers, and it establishes relationship between discomfort and the activity teachers undertaken while working.

The present study aims to determine the incidence of cervicobrachial order discomfort in elementary public schools teachers, from 1 st to 4 th grade, in the city of Pato Branco.

\section{Methods}

According to data collected in 2008 by the Municipal Secretary of Education from Pato Branco, there were 312 effective teachers in 26 (twenty six) schools of early childhood and elementary education. From such data, the population has been constituted by all public elementary school teachers, and the sample comprised 160 teachers.

For an element of the population to be part of the sample, the following inclusion criteria should be fulfilled: agreeing to participate, being present in the period of data collection, being a municipal effective teacher, being teaching as an elementary teacher. Exclusion criteria include: being a trainee, or not a municipal effective teacher; teachers on sick leave or unpaid leave, a teacher who for some reason was absent in the workplace on the day we collected the data, directors and supervisors; being a physical education teacher.

Schools were randomly visited with prior appointment with the respective directors of each school. Each participant was informed about the objectives and their role in this research, through a term of free consent. For data collection, a questionnaire was applied (Annex 1), containing 22 questions, either closed and or multiple choice questions, and also a structured interview for physical examination (Annex 2) which has been applied by the researcher. Both were developed and validated by the authors of this study. The practical application of the research started in $26 / 07 / 2006$, and ended in 06/09/2006. 


\section{Results}

After analyzing and quantifying the data, the elementary public school teachers' profile from Pato Branco-PR could have been known, as well as the situation they are in. The gender distribution showed that the sample composition was almost exclusively female with a percentage of $99.4 \%$ and $0.6 \%$ of males. With regard to the average age of the population, represented by 37.2 years, it is a mature population, with some degree of variability as shown by the standard deviation; this makes the analysis of the results even more relevant as shown in Table 1.

Table 1 - average age of the population

\begin{tabular}{c|c|c|c}
\hline $\begin{array}{c}\text { Minimum } \\
\text { age }\end{array}$ & $\begin{array}{c}\text { Maximum } \\
\text { age }\end{array}$ & Average & $\begin{array}{c}\text { Standard } \\
\text { deviation }\end{array}$ \\
\hline 22 & 62 & 37,2956 & 8,29637 \\
\hline
\end{tabular}

In relation to length time of employment shown in Chart 1 , the analyzed population presented the same rate of $25 \%$ with time of employment from 6 to 10 years, and 16 to 20 years.

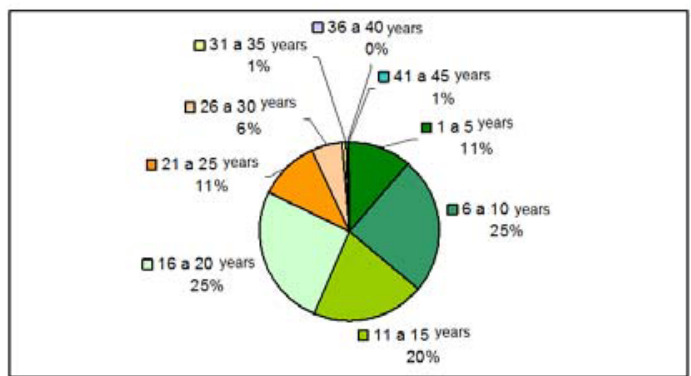

Figure 1 - Length time of employment

Regarding to workload, Table 2, most teachers are inserted into a journey of 40 hours per week, which corresponds to $81.3 \%$.

\begin{tabular}{c|c|c|c}
\hline & Frequency & $\begin{array}{c}\text { Valid } \\
\text { percetage }\end{array}$ & $\begin{array}{c}\text { Cumulative } \\
\text { percentage }\end{array}$ \\
\hline $\begin{array}{c}20 \text { hours a } \\
\text { week }\end{array}$ & 22 & 13,8 & 13,8 \\
\hline $\begin{array}{c}40 \text { hours a } \\
\text { week }\end{array}$ & 130 & 81,3 & 95 \\
\hline $\begin{array}{c}50 \text { or } 60 \text { hours } \\
\text { a week }\end{array}$ & 8 & 5 & 100 \\
\hline TOTAL & 160 & 100 & \\
\hline
\end{tabular}

Table 4 - Distribution of workload
The level of fatigue reported by the teachers showed a percentage of $89.4 \%$, as it is reported in Chart 2.

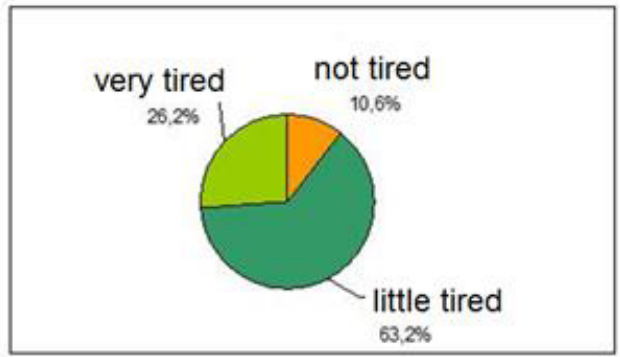

Chart 2 - Level of fadigue

Chart 3 reports the level of teachers' satisfaction with the profession, $66.9 \%$, and dissatisfaction, $28.8 \%$.

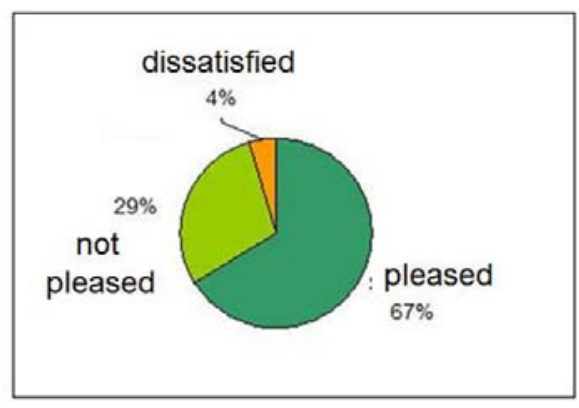

Chart 3 - Satisfaction with the Profession

Chart 4 shows the pain complaints reported by the teachers, where they are located in the regions between the neck and shoulder, with a higher incidence of discomfort or pain in the trapezius muscle, suggesting the presence of pain, in this case, by tension [11].

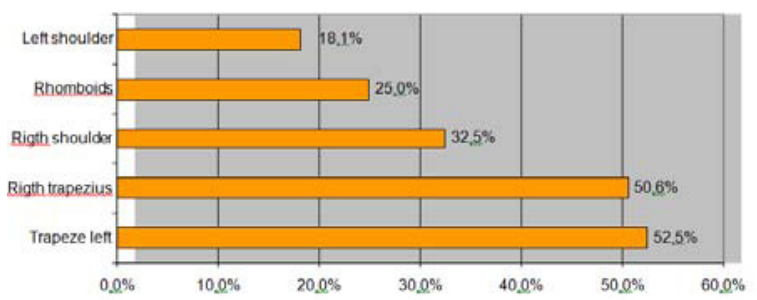

Chart 4 - Locations where there is presence of pain and its impact

Considering that the results indicate high levels of pain in the trapezius muscle, Charts 5 and 6 describe the type of symptoms present in this region. 


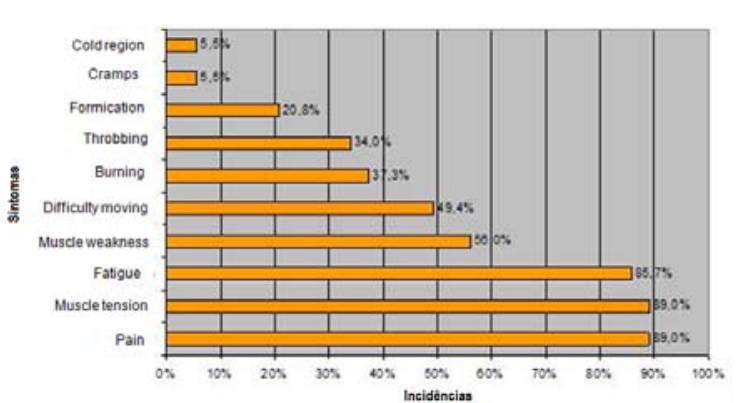

Chart 5 - Symptoms in the left trapezius muscle

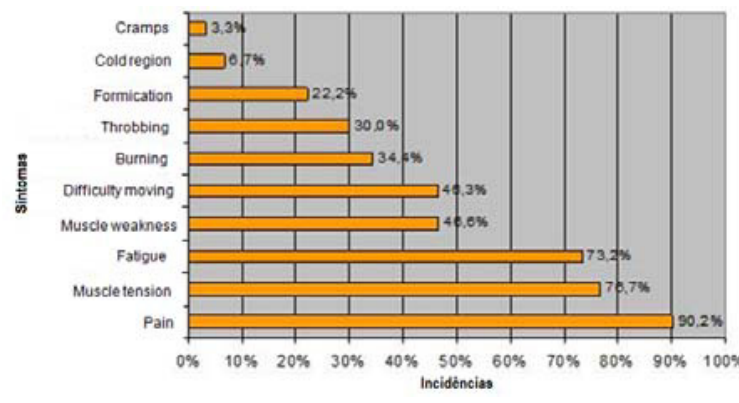

Chart 6 - Symptoms in the right trapezius muscle

According to the charts above, pain, muscle tension and fatigue are the main symptoms reported by the teachers.

\section{Discussion}

The indicated gender distribution with $99.4 \%$ of women has been justified research showing that there are much more women in educational institutions, especially in elementary schools, because this school has became a predominantly female environment [12]. All of this is a consequence from the last century policy, when women could only study in "cursos normais", to be prepared to become an elementary teacher. The result has been a kind of identification of the profession with feminility.

With regard to the average age of the population, represented by 37.2 years old, it demonstrates a mature population, with some degree of variability as shown by the standard deviation of 8.2 , which makes the analysis of results more relevant.

The length time of employment, as reported in Table 1 , shows a rate of $25 \%$ with time of employment from 6 to 10 years, and $25 \%$ from 16 to 20 years the work-related musculoskeletal disorders (DORT). Says that occupational disease does not happen sud- denly, but rather in a gradual way, and almost always with a predictable character [15]. In this sense, according to this author, the understanding of risk factors, or even the understanding of man in his work as well as the context where he operates his activity are essential to overcome the problems caused by DORT, and the preventive measures and attitudes should drive the key actions in this area.

Most teachers, $81.3 \%$, undergo a workload of 40 hour-teaching per week. It is noteworthy that the teachers, besides living with a large workload, often need to take and do some extra-work at home, which reduces their resting and leisure time. Accordin to this study, $61 \%$ of the teachers use their weekends to carry out educational activities, which results in a shorter time to rest, to exercise and to have leisure, which could help them to better their life quality.

The high level of fatigue found among teachers may be a preventing factor to practice physical activity, since $53.8 \%$ of the population does not exercise, and $15.6 \%$ does it only once a week, that may be a predisposition factor to emotional or somatic symptoms.

The high rate of fatigue, $89.4 \%$, according to $\mathrm{Bu}-$ eno, is the most common symptom reported by teachers in a survey conducted in São Paulo due to overcrowded classrooms [14]. In a study by, the complains private school teachers from Vitória da Conquista - BA are mental tiredness $(60 \%)$, pain in arms and shoulders (52\%), backache (51\%), and some other ones of lower inci-dence $[15,16,20]$. In study related to 571 Australian teachers, as having a psychological stress levels twice higher than the population in general [21].

This study also found that $66.9 \%$ of teachers are satisfied with their profession, and $28.8 \%$ are not. No justification has been found in the literature for this high rate of satisfaction. According the teaching profession today is no longer attractive due to low wages and loss of "status". As the teachers have not been questioned about salaries, their answers can only be related to how they feel independently of wages [17].

The mechanism of pain by tension, described by is due to sustained isometric muscle, which causes ischemic muscle pain, also known as myofascial pain. This kind of contraction causes accumulation of metabolites that become irritating causing muscle contraction, which in turn constrict the intrinsic vascular system, decreasing blood flow which results in ischemia [8]. This type of muscle pain is usually caused by anxiety and occupational posture. Strong isometric contractions cause micro-ruptures of muscle fibers and edema formation. Emotional or postural stress may be considered a trauma to the 
al stress may be considered a trauma to the cervical spine, and it can cause pain and incapacity to work.

From the viewpoint of biomechanics, the activity of writing on the board involves anatomical movements that activate the following muscles: deltoid, supraspinatus, infra-spinous, teres minor, trapezius and rhomboids. When the arm starts to be taken forward the activity of the latissimus dorsi and pectoralis major starts. From this description, the teacher remains in the same positions, but the flexion of the shoulder will be higher, there will be a shoulder abduction and the elbow will be in internal rotation.

In this sense, according to pains in the shoulders and neck can occur when working with raised arms, unsupported, for a long time; such conditions may be observed in teachers' daily routine [18]. As puts it, neck-shoulder disorders have as occupational factors working with the arms hanging and static muscle loading [19]. This posture can cause pain and stiffness in the shoulders and the forced tilt of the neck / head can result in pain and stiffness in the neck.

Symptoms such as tension, burning and loss of mobility are, displayed signs in situations where there is the presence of muscle tension in the neck. For the author, the presence of muscle tension can be either a result of maintenance of postures through isometric contractions or from emotional origin [8].

In this case it should be noted that there are two possible causes for the presence of muscle strain in teachers, the first one is an ergonomic factor related to the act of writing on the board, and the other one, a great stress produced by the profession itself, say there is a great psychological suffering in these professionals [16].

It is known that there is limitation of motion in cases without muscle tension, but there is controversy as to its cause, which may be related to structural joint changes, changes in soft tissues, presence of muscle spasm, pain, anxiety or fear [8].

The most reported symptoms, i.e, pain, tension, fatigue and muscle weakness are problems directly related to the points of muscle tension. The presence of moving difficulties may represent a more advanced stage where the symptoms themselves may be preventing you from moving. The sensation of burning, throbbing and tingling are symptoms that are not present in all cases, but are also related to the presence of muscle tension, especially by the ischemic factor that is involved in the process, as it has already been explained.

The fatigue in the case of isometric contraction, results from ischemia caused by contraction, as it has already been mentioned. Muscle weakness is present in more advanced stages of the disease. When there is the presence of muscle tension, the muscle becomes easily fatigable and persistence of this stress tensor leads to muscle weakness from disuse due to the presence of pain, which also makes it difficult to move [19].

This tension may be related to several aspects that are seen as characteristic of the profession, for example, to keep the arm high for some time, requiring sustained contraction of the trapezius, and on the other side, there is usually help of the trapezius when the member is holding an object, like a notebook, for a long time, and also by maintained posture to correct and prepare activities, or either as focal point of emotional tension [8].

Bibliographic findings in this study showed that professionals who work with early childhood education have a great emotional stress that may negatively influence their mental and physical health. The region of the trapezius muscle, related to muscle tension, was the place referred to as most painful and discomfortable. The pathologies that affect the shoulder are mainly the inflammatory and degenerative ones, and the ones affecting the trapezius and rhomboids are related to muscle tension, so you can see there is a greater problem related to the muscle tension than to inflammatory processes.

Considering the obtained results, the need to better the assistance to education professionals with preventive or even curative programs becomes important to improve their live quality. Multiprofessional care is needed for these workers, since their emotional problems, in some cases, may turn into physical problems.

\section{References}

[1] Primary Education Department. National Curriculum: an introduction to the national curriculum guidelines. Vol 1. Brasília: MEC / SEF, 1997.

[2] Novoa, A. Profession. 2nd ed. Collection of Education Sciences. Portugal: Porto, 1995.

[3] Zaragoza, JM teacher malaise: the classroom teachers and health. New York: Edusc, 1999.

[4] Reis, EJFB, Carvalho FM, Araújo TM, Porto LA, Silvany Neto AM. Work and psychiatric disorders in teachers. Journal of Public Health. 2005; 21:1480-90.

[5] Porto, A.L, et al. Association between mental disorders and psychosocial aspects of the work of teachers. Public Health Journal: Salvador, n. 40 (5), p. 818-26. 2006.

[6] Silvany, Neto AM, Araújo TM, Kavalkievicz C, et al. Working conditions and health of teachers in private schools in Bahia: Pilot Study. Journal of Occupational Health. 1998, 24 (91:115-24. 
[7] Araujo, T. M.; relx, E.; Neto. A.; Kavalkievicz, C. Processes Wear Health Teacher. Textual Magazine: 2003

[8] Cailliet, R. Neck and Arm Pain. 3rd ed. Porto Alegre: Artmed, 2003.

[9] Politis, E., Bergamaschi, E. C. Labor Gymnastics: theory and practice. 2nd ed. Rio de Janeiro: Sprint, 2003.

[10] Barbosa, L. G. Preventive Therapy in Work-Related Musculoskeletal Disorders - DORTs: physiotherapy job applied. Rio de Janeiro: Guanabara Koogan, 2002.

[11] Gould, J. A., Physical Therapy in Orthopedics and Sports Medicine. São Paulo: Editora Manole, 1994.

[12] Perozim, L. Men and Women: plural. Education Magazine. Ed 109. New York: Segment, 2006.

[13] Couto, Hudson. A. Ergonomics Applied to Work: Technical Manual of the Human Machine. Volumes I and II. Belo Horizonte, Ergo, 1995.

[14] Bueno, E. I. The Occupational Health Paranaense de Professores.2004 Association

[15] Delors, J. Education: The Treasure Within. 6th ed. São Paulo: Cortez, Brasilia, DF: MEC:
UNESCO, 2001.
[16] Gasparini, S. M., Barreto, S. M.; Asuncion, A. A. Professor, working conditions and the Effects on Health New York: 2005.

[17] Codo apud Delcor, S. N. Health and Working Conditions of Teachers of private schools in Vitória da Conquista BA. Dissertation. Department of Medicine, School of Postgraduate Medicine and Health, Federal University of Bahia in 2003.

[18] Weerdmeester, B. Dul, J. Ergonomics Practice. New York: Edrgar Blucher, 2000.

[19] Mendes, R. Pathology of Labor. Rio de Janei ro: Athena, 1995.

[20] Kavalkievicz C, et al. Working conditions and health of teachers in private schools in Bahia: Pilot Study. Journal of Occupational Health. 1998, 24 (91/2):11524.

[21] Delcor NS, Araújo TM, Reis EJFB, Porto LA, Carvalho FM, Silva MO, et al. Working conditions and health of teachers in private schools in Vitória da Conquista, Bahia, Brazil. Journal of Public Health. 2004; 20:187-96 